\title{
Clay Nanoparticles Composite Membranes Prepared with Three Different Polymers: Performance Evaluation
}

\author{
Raphael Rodrigues, Ana Carolina Daniel Morihama, Izabela Major Barbosa, \\ Gracyelly Nuves Leocádio and José Carlos Mierzwa*
}

\author{
Department of Hydraulic and Environmental Engineering, Polytechnic School, University of Sao Paulo, Av. \\ Prof. Almeida Prado, 83 - Trav. no. 2, São Paulo, SP, CEP 05508-900, Brazil
}

\begin{abstract}
This paper presents the results obtained from the evaluation of clay nanoparticles as an additive for improving the characteristics and performance of composite membranes cast with polysulfone (PS), polyethersulfone (PES), and polyvinylidene fluoride (PVDF). Different concentrations of clay nanoparticles, ranging from 1 to $10 \%$ based on the polymer mass, were used to prepare all dope solutions. The addition of clay nanoparticles changed the internal pore morphology of membranes, which resulted in significant changes on their performance, regarding its water permeability, and fouling potential. The optimum nanoclay concentration for permeability enhancement was different for each polymer, $1.5 \%, 2.0 \%$, and $6.0 \%$ for PS, PES, and PVDF, respectively. This difference can be attributed to the differences of polymer's hydrophobicity, based on the contact angle of a sessile water drop, which is higher for PVDF (PVDF is more hydrophobic than PS and PES). The flow improvement changed based on the main polymer. Significant changes in internal pore structure were observed for all membranes. The proportion of macrovoids was decreased and pores had a better connectivity across the cross section for PES and PS membranes. For PVDF membranes, the addition of nanoclay had a different effect on their microstructure. In this case, internal pores were $20 \%$ wider, factor that increased the average membrane porosity. The simultaneous evaluation of the clay nanoparticles used as an additive have clearly demonstrated its potential application for composite membrane production. It is also worth to note that the best way for identifying and evaluating the potential for an additive for membrane casting is considering its effects for different polymers, under the same casting conditions.
\end{abstract}

Keywords: Clay nanoparticles, polysulfone, polyethersulfone, PVDF, composite membranes.

\section{INTRODUCTION}

Ultrafiltration (UF) and microfiltration (MF) membranes have been widely used in the last 50 years to remove pathogens from water [1]. One of the main drawbacks of membrane systems operation is the adsorption of fouling compounds, which often causes a rapid decline on membrane flux. Fouling refers to the deposition or precipitation of feed components over the membrane surface and/or within its pores. [2-5].

The membrane's base material affects structural properties, such as pore size, roughness and hydrophilicity. This study evaluated the modification of membranes made with three base polymeric materials: polysulfone, (PS), polyethersulfone (PES) and polyvinylidene fluoride (PVDF). The modification of the membrane structure is a method for improvement of surface properties aiming to make the material less prone to fouling.

Many industrial fields use PS and PES as common materials for membrane synthesis due to their good membrane forming ability, acidic and alkaline resistance and mechanical resistance [5-7]. PVDF is a

*Address correspondence to this author at the Av. Prof. Almeida Prado, $83-$ Trav. no. 2, Sao Paulo, SP, CEP 05508-900, Brazil; Tel: +55 (11) 3091-5329; E-mail: mierzwa@usp.br fluoropolymer which has been considered as a good candidate for hydrophobic membrane synthesis due to its low surface tension derived from the low polarity and strong electro-negativity of the fluorine atom and the strong $\mathrm{C}-\mathrm{F}$ bond [8]. The hydrophobic nature of PS, PES and PVDF polymers, in different levels, often results in severe membrane fouling. The permeability decline because of the fouling is a considerable limitation for its practical applications for water treatment.

A huge challenge still faced by the scientific community is to engineer efficient hydrophilic membranes with antifouling properties. Considering the advancements in the nanotechnology field, the application of nanoparticles into the membrane synthesis field created a vast new field of possibilities for research. Some nanocomposite membranes have the desired antifouling capabilities, while other have improvements in other properties such as mechanical strength, porosity, morphology, abrasive resistance or hydraulic performance [9]. Among the various nano additives used, such as alumina [10], titanium oxide [11,12], silver, [13,14], zinc oxide [15], carbon nanotubes [16], and graphene oxide [17], nanoclay has been widely used for being easily commercially available and having the ability to be easily dispersed into the polymeric matrix at nanoscale [18-22]. 
When clay nanoparticles are employed in the process of membrane synthesis, they can improve mechanical properties and performance of the resulting membrane. The addition of clay nanoparticles on dope solution can result in membranes with increased permeability $[18,21,22]$, gas diffusivity $[23,24]$, thermal resistance [25,26], resistance to abrasion [27] and improved surface properties, because of strong polymer and clay interactions .

Considering the benefic effects of clay nanoparticles used for the production of composite membranes, many researchers started to evaluate their effects on the properties and performance of composite membranes. Table 1 presents the main papers related to the evaluation of clay or clay nanoparticles as an additive for composite membrane production.

The listed studies presented different membrane casting methodologies and different compositions. The comparison of the results makes a challenge the effort to understand the role of clay nanoparticles on the changes on membranes structure and performance.

For this reason, this study brings novelty to this field of science by evaluating the effect of clay nanoparticles addition on the structure and performance of membranes cast with different polymers at similar conditions. The main objective is to clarify many aspects regarding the role of clay nanoparticles on the structure of composite membranes. The main challenges faced in this study clearly demonstrated the relevance of a complete and uniform approach for understanding the role of specific additives on the properties and performance of modified membranes.

\section{MATERIALS AND METHODS}

\subsection{Chemicals}

Polysulfone (UDEL $®$ P-3500) and Polyethersulfone (VERADEL 3000P) were kindly donated by Solvay Advanced Polymers. Polyvinylidene Fluoride, PVDF Kynar 761, was kindly donated by Arkema Química Ltd. Polymers were used as received.

1-methyl-2-pyrrolidone $>99 \%$ (NMP) was used as solvent without further purification. The clay nanoparticle (Montmorillonite Nanomer ${ }^{\circledR}$ PGV Sigma Aldrich) is a single platelet montmorillonite of formula $\mathrm{M}_{\mathrm{y}}^{+}\left(\mathrm{Al}_{2-\mathrm{y}} \mathrm{Mg}_{\mathrm{y}}\right)\left(\mathrm{Si}_{4}\right) \mathrm{O}_{10}(\mathrm{OH})_{2} \cdot \mathrm{nH}_{2} \mathrm{O}$, where $\mathrm{M}$ are lower valence cations yielding a cation exchange capacity of 1.45 meq. $\mathrm{g}^{-1}$. The approximate dimensions of the individual montmorillonite platelets are $1 \mathrm{~nm} \times 150-200$ $\mathrm{nm} \times 150-200 \mathrm{~nm}$. Deionized water was prepared in the laboratory by double step reverse osmosis and used for membrane coagulation bath and membrane performance evaluation.

Table 1: Comparison of Studies Using Nanoclays on Membrane Modification

\begin{tabular}{|c|c|c|c|c|c|c|}
\hline & $\begin{array}{l}\text { ANADÃO et al. } \\
(2010)[28]\end{array}$ & $\begin{array}{l}\text { MONTICELLI et al. } \\
(2006)[18]\end{array}$ & $\begin{array}{l}\text { MA et al. } \\
(2012) \text { [29] }\end{array}$ & $\begin{array}{l}\text { GHAEMI et al. } \\
\text { (2011) [22] }\end{array}$ & $\begin{array}{l}\text { RAJABI et al. } \\
\text { (2014) [21] }\end{array}$ & $\begin{array}{l}\text { Lai et al. (2014) } \\
\text { [27] }\end{array}$ \\
\hline Polymer & PS & PS & PS & PES & PVDF & PVDF \\
\hline Polymer concentration & $25 \%$ & $25 \%$ & $13,50 \%$ & $20 \%$ & $18 \%$ & $14.25 \%$ to $15 \%$ \\
\hline Solvent & NMP & NMP & $\mathrm{DMAc}^{1}$ & $\mathrm{DMF}^{2}$ & $\mathrm{DMF}^{2}$ & NMP \\
\hline Nanoclay concentration & $\begin{array}{l}0,5 \% \text { to } 3 \% \\
\text { (solution) }\end{array}$ & $\begin{array}{l}2 \% \text { to } 5 \% \\
\text { (solution) }\end{array}$ & $\begin{array}{l}1 \% \text { to } 6 \% \\
\text { (polymer) }\end{array}$ & $\begin{array}{c}0,5 \% \text { to } 10 \% \\
\text { (solution) }\end{array}$ & $\begin{array}{l}1 \% \text { to } 6 \% \\
\text { (solution) }\end{array}$ & 1 to $5 \%$ \\
\hline Pore Former & & & $6 g$ PEG400 & $2 \% \mathrm{PVP}^{3}$ (solution) & $\begin{array}{l}1 \% \mathrm{PVP}^{3} \\
\text { (solution) }\end{array}$ & \\
\hline Thickness & & $350 \mu \mathrm{m}$ & $200 \mu \mathrm{m}$ & $250 \mu \mathrm{m}$ & $250 \mu \mathrm{m}$ & $300 \mu \mathrm{m}$ \\
\hline Permeate flow & & increased & increased & increased & increased & decreased \\
\hline Rejection & & increased & decreased & increased & & \\
\hline Hydrophilicity & increased & same & same & increased & increased & \\
\hline Porosity & & & increased & & increased & \\
\hline Mechanical Resistance & increased & decreased & decreased & same & & increased \\
\hline Thermal Resistance & increased & & & increased & & increased \\
\hline
\end{tabular}

1 - DMAc Dimethylacetamide.

2 - DMF Dimethylformamide.

3 - PVP Polyvinylpyrrolidone. 


\subsection{Membrane Synthesis}

The membrane dope solutions preparation followed the same procedure for the three polymers, as it follows:

I) A fixed mass of polymer (PS, PES or PVDF) representing $18 \%$ of solution weight was mixed in NMP. The nanoclay additive was measured based on the polymer weight.

II) The dope solutions were prepared by dispersing the nanoclay (when applicable), in the NMP and then dissolving the polymer. The same procedure was previously described in the literature [30-32].

III) The solution stirring has taken 24 hours at 120 $\mathrm{rpm}$, to ensure the adequate clay dispersion and polymer solubilization. Prior to the phase inversion process, an ultrasonic bath (30 minutes) degassed the solution, eliminating air bubbles trapped during the mixing process.

IV) After mixing and degassing, the solutions were spread on glass plates using a film applicator (Elcometer 4340 Automatic Film Applicator for PES and PS membranes / ELCOMETER K4340 M10 for PVDF membranes) and then quickly immersed (<5 s) into a coagulation bath containing deionized water at room temperature.

V) After detaching from the glass plate in the coagulation bath, the membranes were placed in a second deionized water bath at room temperature ( $>24$ hours) to remove any residual solvent.

\subsection{Sample Classification}

For the study, membranes were named according to the base polymer and the clay nanoparticles percentage. i.e. PS-X, PES-Y and PVDF-Z, are membranes made with Polysulfone with $X \%$ of nanoclay, Polyethersulfone with $\mathrm{Y} \%$ of nanoclay and Polyvinylidene Fluoride with $\mathrm{Z} \%$ of nanoclay, respectively.

\subsection{Membrane Characterization}

\subsubsection{Pure Water Permeability - Cross-Flow Filtration}

The test to evaluate membrane permeability consisted in challenging the membranes in a cross-flow configuration fed with demineralized water. The permeability test defined which membranes would be further evaluated and compared with the best permeability membranes made from other polymers.

The cross-flow test cell used for the test was a bench scale unit designed with a commercial flat-sheet filtration cell with $34 \mathrm{~cm}^{2}$ of filtration area, a pump, a pressure gauge and a thermometer. Deionized water was pumped into the filtration cell and the rejected water was recycled back to the feed reservoir. Permeate was collected every five minutes in a graduated cylinder over one hour of filtration period, to measure the permeate flow rate. The permeate tubing was open to the atmosphere and the permeate pressure was considered to be constant at 1 bar (absolute). The permeability was calculated using the equation (1):

$$
P=\frac{V}{A \times \Delta t \times \Delta P}
$$

In which $P$ is the membrane permeability $\left(\mathrm{L} \mathrm{m}^{-2} \mathrm{~h}^{-1}\right.$ bar $\left.^{-1}\right), V$ is the volume of permeate collected (L), $A$ is the effective membrane area $\left(\mathrm{m}^{2}\right), \Delta t$ is the permeate collection time $(\mathrm{h})$, and $\Delta \mathrm{P}$ is the transmembrane pressure (bar)

\subsubsection{Contact Angle Measurements}

Contact angle measurements were taken with a goniometer (Ramé-Hart Instrument Co.; Model 190 CA) using the sessile drop technique. The membrane preparation and contact angle measurement were carried out according to the ISO 15989 Standard Procedure [33]. Three samples of each membrane were evaluated. Each sample had at least 30 measurements.

\subsubsection{Membrane Porosity and Thickness}

The method used to determine membrane porosity was previously reported (wet/dry weight method) $[30,31]$. The wet weight was measured after removing the superficial water from membrane sample using two polyester/cellulose wipers and the dry weight was measured using a digital micrometer (Fowler Tools and Instruments; 1.27 to $25,400 \mu \mathrm{m}$ ) after drying the samples. The porosity was calculated using the equation (2):

$$
\in(\%)=\frac{\frac{m_{1}-m_{2}}{\rho_{w}}}{V_{m}}
$$


in which, $m_{1}$ and $m_{2}(g)$ are the wet and dry weights, $\rho_{w}$ $\left(\mathrm{g} / \mathrm{cm}^{3}\right)$ is the water density $\left(0.998 \mathrm{~g} / \mathrm{cm}^{3}\right), V_{m}\left(\mathrm{~cm}^{3}\right)$ is the membrane volume, and $\varepsilon(\%)$ is the bulk porosity. The volume, $V_{\mathrm{m}}$, was calculated by multiplying the sample area by its thickness, which was measured using a digital micrometer.

\subsubsection{Morphological Analysis}

Scanning Electronic Microscopy (SEM) images were taken to analyze membrane cross-sections. In order to preserve the cross-section's structure, the samples were first immersed in liquid nitrogen for $30 \mathrm{~s}$ and then cleanly snapped.

PES membrane images were taken at Harvard University's Center for Nanoscale Systems using a Field Emission Scanning Electron Microscope (Zeiss FESEM Ultra 55), as described previously [31]. PS and PVDF membrane images were taken using a Quanta 600FEG Environmental Scanning Electron Microscope (ESEM), operating in secondary electron detection mode with a $10 \mathrm{kV}$ accelerating voltage.

PS and PVDF samples were coated with a modular high vacuum coating system (BAL-TEC MED 020) resulting in an $\sim 10 \mathrm{~nm}$ platinum layer after 120-160 s of deposition using a electrical current of $43 \mathrm{~mA}$.

\subsection{Membrane Molecular Weight Cut-Off}

To determine the molecular weight cut-off (MWCO), membranes were challenged in the same cross-flow cell used for ultrapure water permeability using PEG feed solutions with molecular weights of $10,20,30,90$,
150 and $203 \mathrm{~kg} \mathrm{~mol}^{-1}$. The feed and permeate PEG concentrations were determined using the nonpurgeable organic carbon (NPOC) method on a TOC analyzer (Shimadzu; TOC-VWS). The feed contained approximately $20 \mathrm{mgC} \mathrm{L}^{-1}$ of the chosen PEG (NPOC equivalent) in ultrapure water. Samples were collected after one hour of operation for at least three membrane samples. Rejection $(R)$ was defined by the following equation:

$R(\%)=\left(1-\frac{C_{p}}{C_{f}}\right) \times 100$

where $C_{p}$ and $C_{f}$ are the NPOC concentrations in the permeate and feed, respectively.

\subsection{Data Analysis}

Excel® Software, 2013, from Microsoft Inc., was used for statistical analysis and graphic construction. Igor Pro $®$ was used to design the sigmoid curves for molecular weight cutoff evaluation. In the figures, the box and Whiskers plots present the values of mean, minimum and maximum values (bar), and first and third quartiles (box) of the data set. The software Image-J (Public Domain license) was used for refining SEM images.

\section{RESULTS AND DISCUSSION}

\subsection{Cross-Flow Permeability}

Figure 1 depicts the pure water cross-flow permeability results. Mixed matrix membranes had an

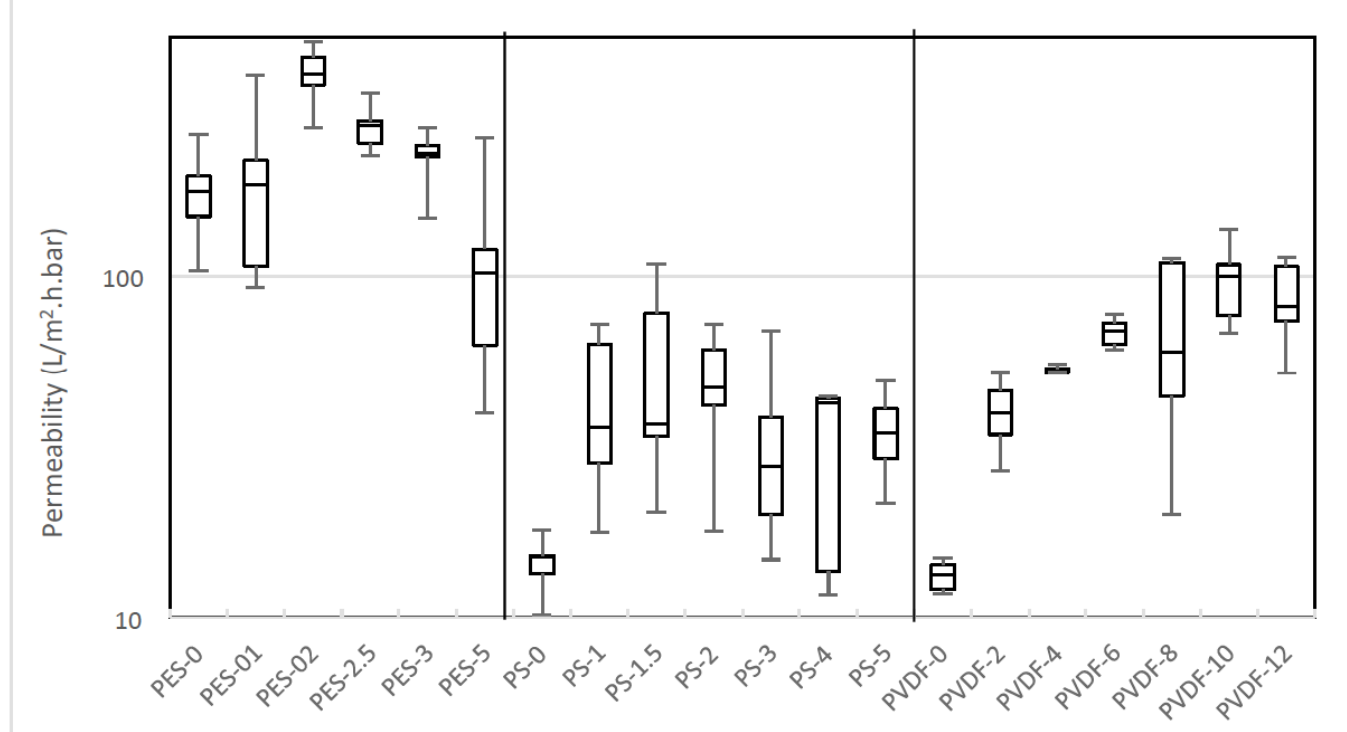

Figure 1: Membranes Permeability. 
Table 2: ANOVA Comparing Membrane Permeability

\begin{tabular}{|c|c|c|c|c|c|c|c|}
\hline $\begin{array}{c}\text { Compared } \\
\text { membranes }\end{array}$ & F & F crit & P-value & $\begin{array}{c}\text { Compared } \\
\text { membranes }\end{array}$ & F & F crit & P-value \\
\hline \hline PS0/PS1 & 9.13 & 4.96 & $1.29 E-02$ & PVDF0/PVDF2 & 71.9 & 4.60 & $6.90 \mathrm{E}-07$ \\
\hline PS0/PS1.5 & 7.35 & 4.96 & $2.19 \mathrm{E}-02$ & PVDF0/PVDF4 & $2.68 \mathrm{E}+03$ & 4.84 & $1.71 \mathrm{E}-14$ \\
\hline PS0/PS2 & 1.30 & 5.32 & $6.90 \mathrm{E}-03$ & PVDF0/PVDF6 & $6.51 \mathrm{E}+02$ & 4.60 & $3.87 \mathrm{E}-13$ \\
\hline PS0/PS3 & 5.16 & 4.49 & $3.72 \mathrm{E}-02$ & PVDF0/PVDF8 & 24.1 & 4.21 & $3.87 \mathrm{E}-05$ \\
\hline PS0/PS4 & 10.4 & 5.59 & $1.46 \mathrm{E}-02$ & PVDF0/PVDF10 & 91.4 & 4.45 & $2.97 \mathrm{E}-08$ \\
\hline PS0/PS5 & 20.4 & 5.59 & $2.73 \mathrm{E}-03$ & PVDF0/PVDF12 & 93.8 & 4.60 & $1.39 \mathrm{E}-07$ \\
\hline PES0/PES1 & 28.4 & 4.26 & $1.80 \mathrm{E}-05$ & PVDF6/PVDF8 & $1.82 \mathrm{E}-03$ & 4.24 & $9.76 \mathrm{E}-01$ \\
\hline PES0/PES2 & $2.02 \mathrm{E}+02$ & 4.26 & $3.35 \mathrm{E}-13$ & PVDF6/PVDF10 & 4.16 & 4.49 & $5.83 \mathrm{E}-02$ \\
\hline PES0/PES2.5 & 9.90 & 4.54 & $6.65 \mathrm{E}-03$ & PVDF6/PVDF12 & 4.14 & 4.75 & $6.46 \mathrm{E}-02$ \\
\hline PES0/PES3 & 5.51 & 4.26 & $2.75 \mathrm{E}-02$ & & & & \\
\hline PES0/PES5 & 10.6 & 4.54 & $5.26 \mathrm{E}-03$ & & & \\
\hline
\end{tabular}

increased permeability compared to their respective controls with a $95 \%$ level of confidence (Table 2). Polyethersulfone membranes' permeability was significantly higher than polysulfone and PVDF membranes.

PES and PS membranes had a permeability trend that shows an increase on average permeability until an optimum concentration of additive. For higher concentrations of additive, the permeability decreases. This behavior is associated with changes on internal membranes morphology, as it will be further discussed.

For PVDF permeability trend, there was not an optimum nanoparticle concentration, as it was observed for PES and PS. The permeability increased with higher concentrations of clay nanoparticles until it stabilized for nanoclay concentrations above $6 \%$. There was no significant statistical difference of the permeability among membrane with nanoclay concentration in the range of 6 to $12 \%$, (Table 2) Increasing nanoclay concentration after $12 \%$ resulted in a bad dispersion of nanoclay and the final membranes would not be uniform in terms of additive (i.e. $14 \%$ and $16 \%$ nanoclay). For this reason, further tests with PVDF membranes considered clay nanoparticles concentrations ranging from $0 \%$ to $6 \%$.

It is worth to note that clay nanoparticles affected the permeability of all the membrane types, regardless their base polymer. This result is positive to show has a high potential of this additive for membrane synthesis.

\subsection{Contact Angle}

The addition of hydrophilic additives is a method to improve membrane hydrophilicity. The hydrophilic additive's strong interaction with water helps on the additive migration to the interface between the casting solution and the coagulation bath during the membrane formation, increasing the membrane surface hydrophilicity $[6,18,21,31]$. The contact angle is a reference to evaluate the surface hydrophilicity changes.

Figure 2 shows the contact angle results for all cast membranes. There was an unexpected behavior on PES membranes as the contact angle increased with nanoclay addition. This behavior can be explained by changes on surface roughness [32], which brings deviation on the formation of the sessile drop on the surface.

The contact angles for PS membranes did not change significantly compared to the control ( $F$ 1.61, $F_{\text {crit }} 2.57$ and $P$-value 0.19), but there was a higher standard deviation compared to the other membranes. Comparing PS and PES, the presence of etheric bonds in the chains of the latter [7] makes the polymer more hydrophilic compared to PS, resulting in lower surface contact angles.

PVDF had the lowest variation on the contact angle measurements. Analyzing the results presented on Figure 2, clay nanoparticle addition reduced membranes' contact angle, even for the small concentration added, reaching a plateau close to 90 degrees. The behavior for PVDF membranes' contact angle variation is quite different from the ones observed for PES and PS composite membranes, which can be associated with the differences on surface roughness [32]. It can be inferred that PVDF 


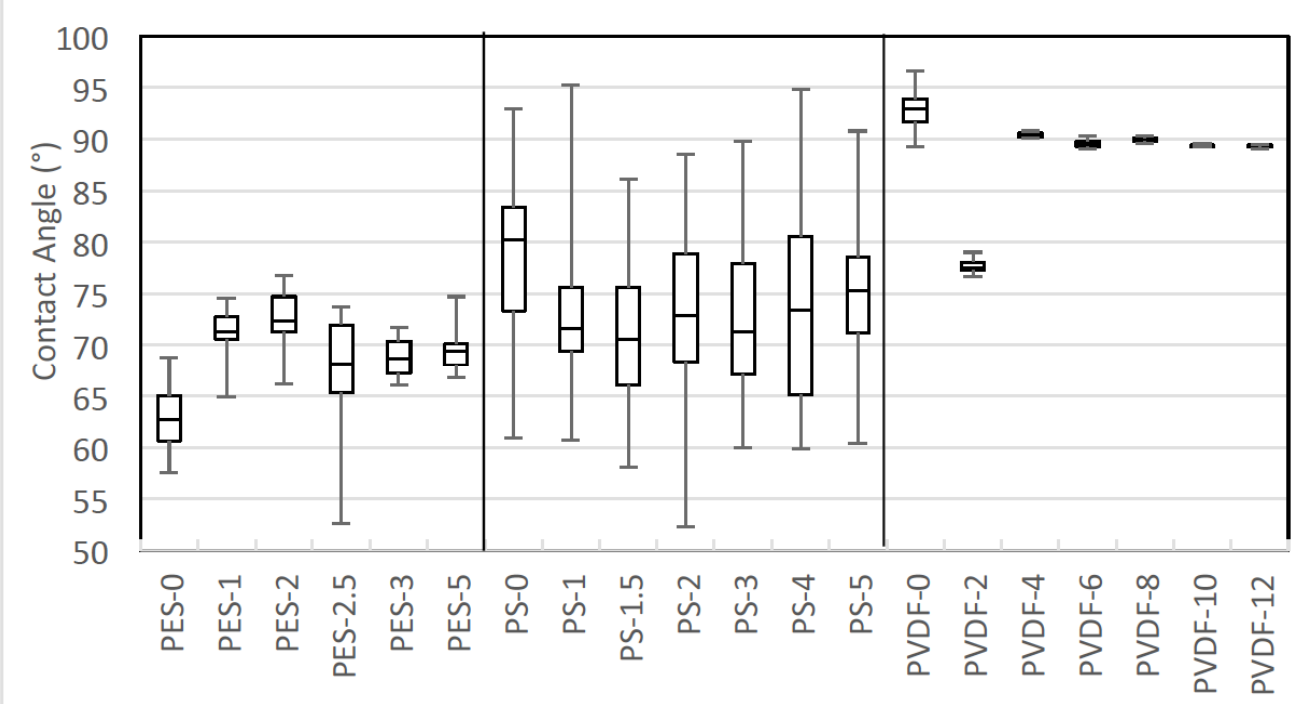

Figure 2: Membrane Contact Angles.

mixed matrix membranes presented a lower roughness compared to the two other membranes, and the effect of hydrophilic clay nanoparticles was more noticeable.

Considering the results, there is no correlation to the changes on mixed matrix membranes contact angle and permeability. This observation reinforces that other surface properties can affect the contact angle, such as surface roughness [24]. According to Khulbe et al. [34], the contact angle is directly related to the membrane surface roughness in a way that the lower the surface roughness, lower is the contact angle.

\subsection{Membrane Porosity and Thickness}

Figure 3 contains the measurements of membrane thickness. PES and PS membranes were initially cast in a $100 \mu \mathrm{m}$ thickness film before the phase inversion. The average shrinkage was $42.7 \%$ and $47.5 \%$ for PES and PS respectively. PVDF membranes were cast initially which a thickness of $120 \mu \mathrm{m}$ to obtain a mechanically stable film by the end of the phase inversion step. PVDF membranes had an average shrinkage of $71.1 \%$. The use of nanoclay as additive influenced the average thickness of PVDF membranes, increasing their thickness on an average of $10 \%$.

The porosity off all samples ranged between $62 \%$ and $84 \%$ (Figure 4). The addition of hydrophilic additives causes a thermodynamic immiscibility in the dope solution, leading to an accelerated solvent and non-solvent exchange that promotes the formation of a porous structure. [35]

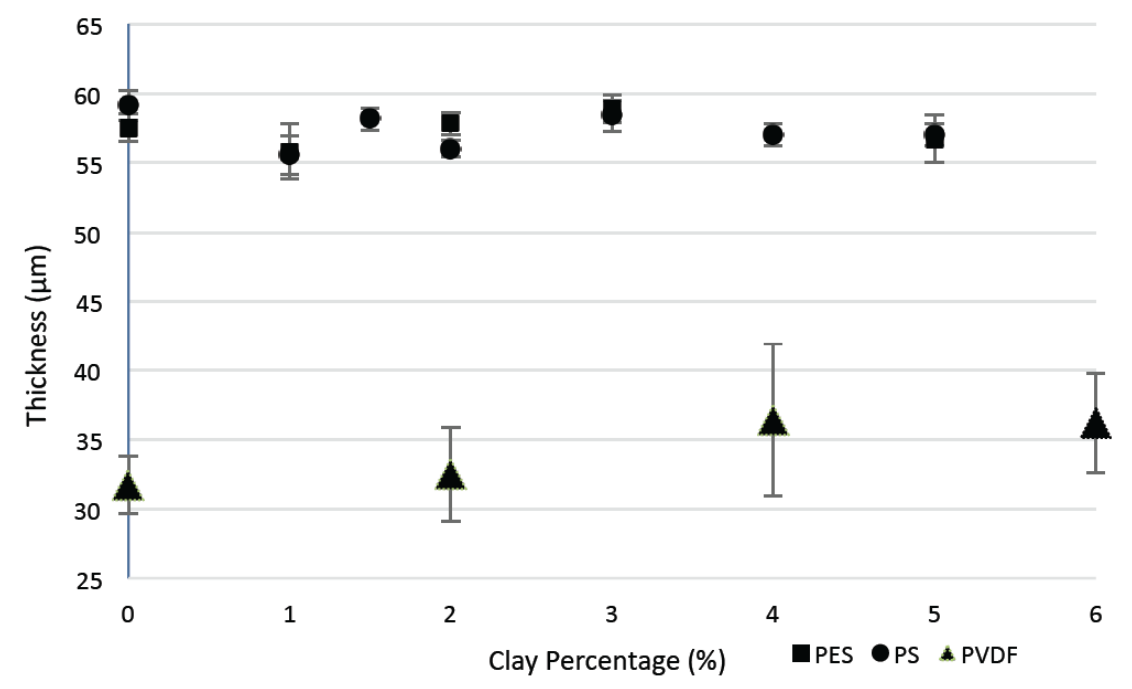

Figure 3: Membrane Thickness. 


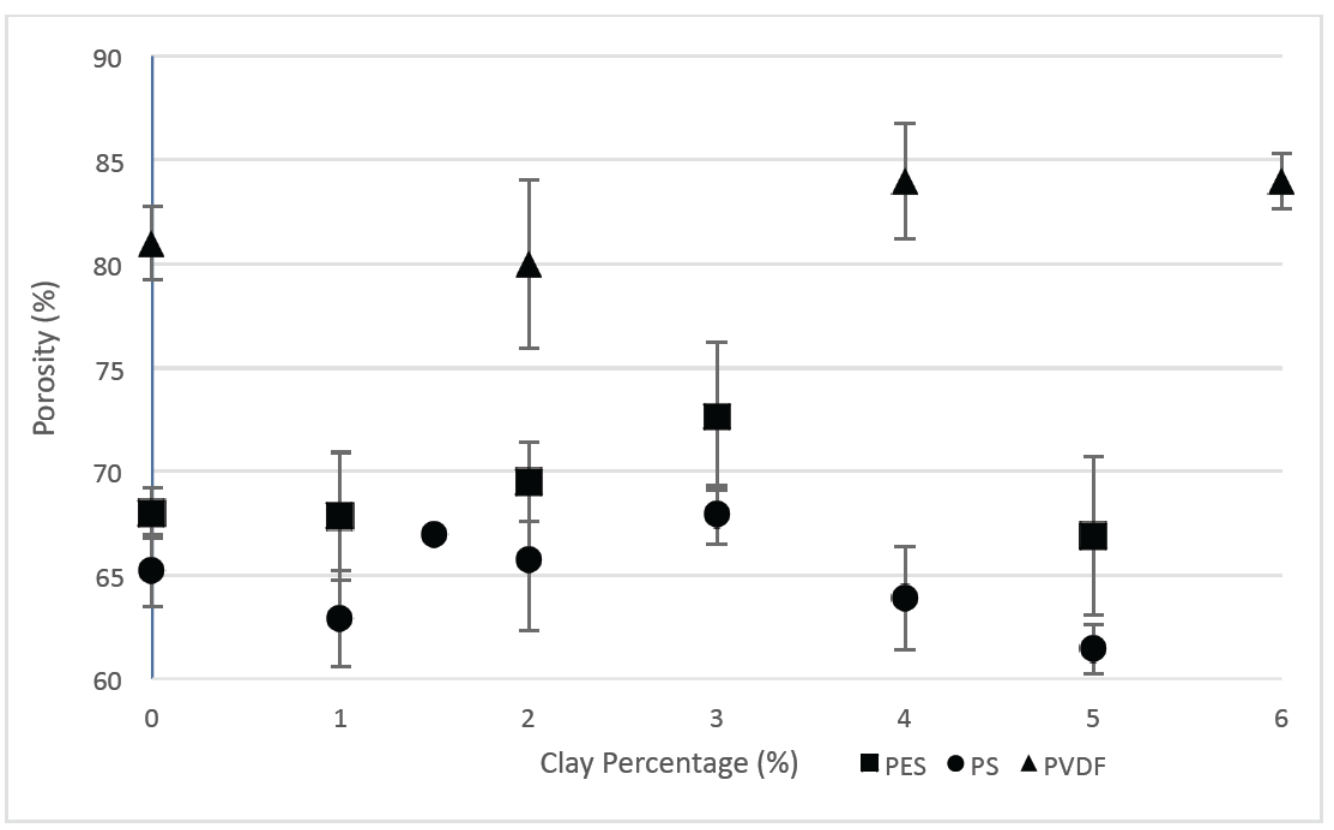

Figure 4: Membrane Porosity.

PVDF membranes showed a calculated porosity higher than other polymers, which can be explained by their thin thickness. Other studies evaluating nanoclay in PVDF membranes also observed a high porosity $[20,36]$. Another factor that explains the high porosity of the PVDF membranes is the large internal pores that can be seen in the cross-section SEM pictures, further detailed on section 3.4. Despite having the highest porosity among the three polymers evaluated, PVDF membranes did not have the highest absolute permeability.

PES and PS had a similar behavior in terms of porosity as nanoclay percentage increased. For both polymers, the porosity increased up to a certain limit and then decreased.

\subsection{Morphology Analysis}

The formation of the membrane internal structure had previously been explained [37-40]. However, the use of additives modifies the kinetics and thermodynamics of the membrane formation process $[40,41]$, impacting on its final structure. As pointed out by Lai et al. [27] and Ma et al. [29], the effects caused by clay nanoparticles on the membrane formation can be explained by an increased demixing rate in the phase inversion process, as the solid nanoparticles made the dope solution thermodynamically less stable.

In order to evaluate those changes, microscopic study through SEM analysis was carried out to have qualitative information about surface and cross- sectional morphology of the membranes with best permeability. Figure $\mathbf{5}$ shows that all membranes had a typical asymmetric porous structure with a thin upper skin layer and a finger-like porous sub-layer.

A morphology comparison between PES and PS membranes shows more finger-like pores for them compared to PVDF. As pointed out by Barth et al. [42], the finger-like structure is a result of the PES's polar nature and its higher affinity to water. The addition of nanoclay resulted in the suppression of the macrovoid zone for both cases and the formation of micropores for PES.

With an increasing on nanoclay concentration, the skin layer thickness decreased and sub-layer structure changed to finger-like structure, leading to a higher porosity and enhanced permeability. For both cases (PES and PS) the length of the finger like structure was larger and the pores were more vertically interconnected. These changes in pore structure across the membranes help to explain why PES membranes had the best absolute permeability.

For PVDF membranes, the cross-section morphologies show sponge-like micro-pores in the lower side and finger-like macro-pores in the upper side of the membranes. The addition of nanoclay did not change significantly the proportion of macrovoids (which was low regardless of clay addition). Nanoclay, however, changed the pore structure resulting in pores $20 \%$ larger than pristine PVDF membranes, and a thinner surface layer. This change in pore structure 

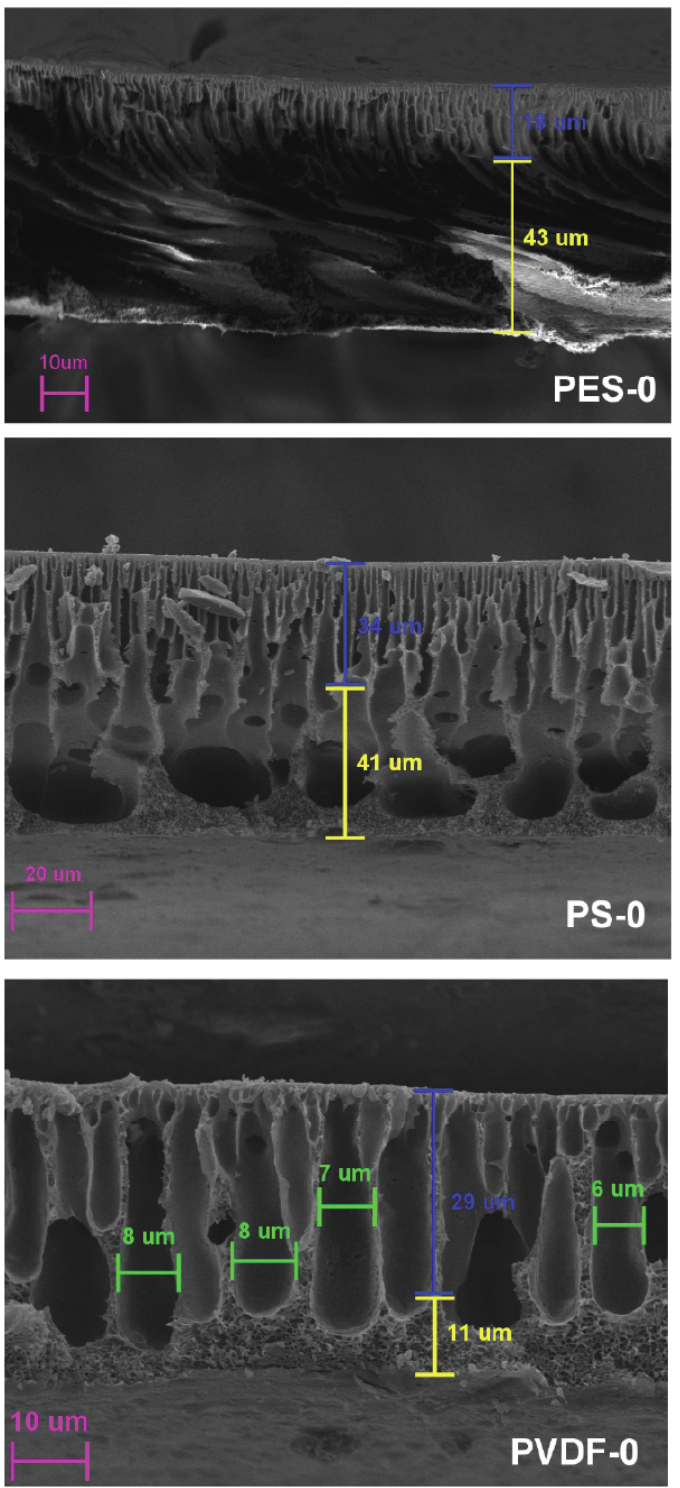

Figure 5: Membranes' Cross Section.

resulted in a higher membrane porosity, and lower resistance for water flow, since membranes were able to hold more water inside the porous structure.

\subsection{Molecular Weight Cutoff}

Comparing the rejection curves showed on Figure 6 , the addition of nanoclay in the membranes solution changed the membrane average molecular weight cutoff (MWCO). PES membrane had a MWCO between 60 and $70 \mathrm{~kg} / \mathrm{mol}$, whereas the nanoclay counterpart's was between 80 and $90 \mathrm{~kg} / \mathrm{mol}$. For PS membranes the additive did not significantly change the rejection. Both PS membranes had an average MWCO between 90 and $100 \mathrm{~kg} / \mathrm{mol}$. PVDF membranes had the lower rejection ability, with MWCO between 170 and $180 \mathrm{~kg} / \mathrm{mol}$ for the membrane without


additive and between 190 and $200 \mathrm{~kg} / \mathrm{mol}$ for the nanoclay modified membrane.

The use of additives changes the balance between membrane permeability and rejection. To make the membrane more permeable, there is a compensation on average rejection. This trend, however, was not evident for PS membranes. The average permeability increased from 14.2 to $55 \mathrm{~L} / \mathrm{m}^{2}$.h.bar (382\% increase) while the average rejection was not significantly compromised.

The lower rejection level for PVDF membranes can be explained by the internal morphology and increased membrane porosity, which would allow higher molecular compounds to go through the membrane. PVDF is a typical hydrophobic material and PVDF 


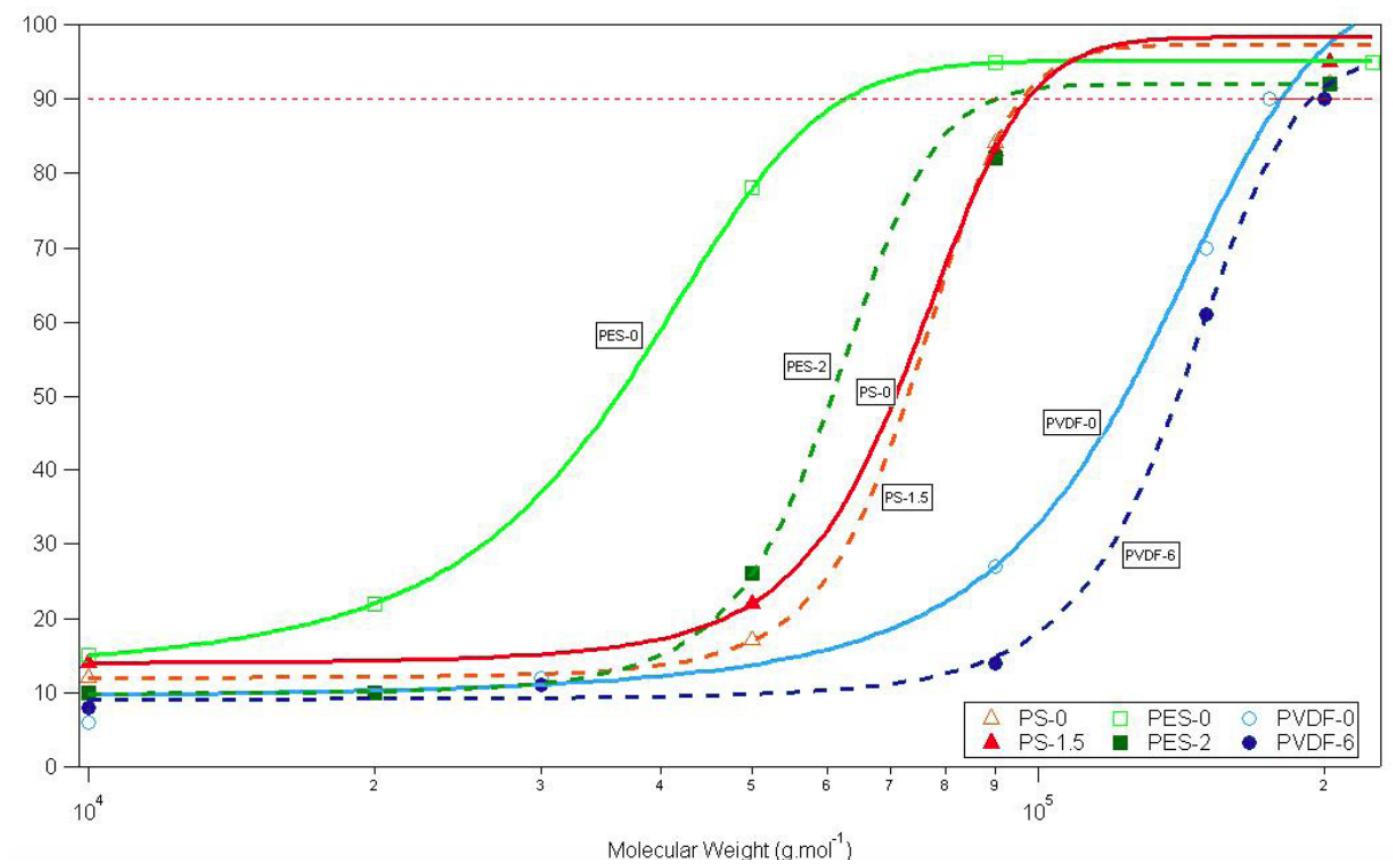

Figure 6: Molecular Weight Cutoff.

membrane is easy to be fouled. As it is pointed by Zeng et al. [43], the surface roughness plays an important role on evaluating the PVDF membrane adsorption on the surface. It is pointed out that hydrophilic nanoparticles could resist the hydrophobic contaminants, increasing the anti-fouling properties of membranes.

\section{CONCLUSIONS}

The effect of nanoclay as additive changed membrane properties based on the original polymer. If the polymer is more hydrophilic, the changes in relative permeability was lower than compared to more hydrophobic polymers. i.e., for PES membranes the permeability improvement was $221 \%$ (from 176 to 389 $\mathrm{L} / \mathrm{m}^{2}$.h.bar), while for PS the improvement was $382 \%$ (from 14.4 to $55 \mathrm{~L} / \mathrm{m}^{2}$.h.bar) and $521 \%$ for PVDF (from 11.7 to $61 \mathrm{~L} / \mathrm{m}^{2}$.h.bar). Different effects were also observed comparing membrane contact angles. For PES (more hydrophilic), the contact angles were increased, making the membranes theoretically slightly more hydrophobic (despite the absolute high permeability). For PS, the nanoclay effect on contact angles was not significant, while for PVDF the contact angles were lowered, making the membranes more hydrophilic. The application of nanoclay as additive showed significant changes in permeability, which can be better explained by changes in the membrane internal asymmetric morphology. For PES and PS membranes, nanoclay changed the internal structure contributing to suppress macrovoids. For PVDF membranes, the morphology changes caused by nanoclay addition were noticeable in membrane porosity, pore width, and surface layer thickness. Differently from PES and PS, the proportion of macrovoids and spongelike structure did not change significantly. However, the additive contributed to increase the PVDF membrane internal pore width by $20 \%$, which implied in lower rejection levels compared to PS and PES. The increase of porosity and pore size of the modified PVDF membranes resulted in the increase of water flux and slight increased the MWCO, which was consistent with the SEM morphologies.

Therefore, the consideration of applying a specific additive for membrane modification, such as nanoclay, must consider the properties of the base polymer according to the needs of the application.

\section{ACKNOWLEDGEMENTS}

The authors thank University of São Paulo's Technological Characterization Laboratory, Harvard's Center for Nanoscale Systems (CNS) for SEM analysis, and to the FINEP for the financial support. R.R. thanks CAPES - Brazil for his PhD fellowship.

\section{CONFLICT OF INTEREST}

The authors declare that there is no conflict of interest regarding the publication of this paper. 


\section{REFERENCES}

[1] Porter MC. Handbook of Industrial Membrane Technology, Noyes Publications 1990.

[2] Gao W, Liang H, Ma J, Han M, Chen Z, Han Z, et al. Membrane fouling control in ultrafiltration technology for drinking water production: A review. Desalination 2011; 272: 1-8.

https://doi.org/10.1016/j.desal.2011.01.051

[3] Guo W, Ngo H-H, Li J. A mini-review on membrane fouling Bioresour Technol 2012; 122: 27-34. https://doi.org/10.1016/j.biortech.2012.04.089

[4] Shi X, Tal G, Hankins NP, Gitis V. Fouling and cleaning of ultrafiltration membranes: A review. J Water Process Eng 2014; 1: 121-138. https://doi.org/10.1016/j.jwpe.2014.04.003

[5] Xu Z, Ye S, Zhang G, Li W, Gao C, Shen C, et al. Antimicrobial polysulfone blended ultrafiltration membranes prepared with $\mathrm{Ag} / \mathrm{Cu} 2 \mathrm{O}$ hybrid nanowires. J Memb Sci 2016; 509: 83-93

https://doi.org/10.1016/j.memsci.2016.02.035

[6] Li S, Cui Z, Zhang L, He B, Li J. The effect of sulfonated polysulfone on the compatibility and structure of polyethersulfone-based blend membranes. J Memb Sci 2016; 513: 1-11.

https://doi.org/10.1016/j.memsci.2016.04.035

[7] Rastegarpanah A, Mortaheb HR. Surface treatment of polyethersulfone membranes for applying in desalination by direct contact membrane distillation. Desalination 2016; 377: 99-107.

https://doi.org/10.1016/j.desal.2015.09.008

[8] Zheng L, Wu Z, Wei Y, Zhang Y, Yuan Y, Wang J. Preparation of PVDF-CTFE hydrophobic membranes for MD application: Effect of LiCl-based mixed additives. J Memb Sci 2016; 506: 71-85. https://doi.org/10.1016/j.memsci.2016.01.044

[9] Woo YC, Kim Y, Shim W-G, Tijing LD, Yao M, Nghiem LD, et al. Graphene/PVDF flat-sheet membrane for the treatment of RO brine from coal seam gas produced water by air gap membrane distillation. J Memb Sci 2016; 513: 74-84. https://doi.org/10.1016/j.memsci.2016.04.014

[10] Yan L, Li YS, Xiang CB. Preparation of poly(vinylidene fluoride)(pvdf) ultrafiltration membrane modified by nanosized alumina (Al2O3) and its antifouling research. Polymer (Guildf) 2005; 46: 7701-7706. https://doi.org/10.1016/j.polymer.2005.05.155

[11] Bae T-H, Tak T-M. Effect of TiO2 nanoparticles on fouling mitigation of ultrafiltration membranes for activated sludge filtration. J Memb Sci 2005; 249: 1-8. https://doi.org/10.1016/j.memsci.2004.09.008

[12] Yang $Y$, Zhang $H$, Wang $P$, Zheng $Q$, Li J. The influence of nano-sized TiO2 fillers on the morphologies and properties of PSF UF membrane. J Memb Sci 2007; 288: 231-238. https://doi.org/10.1016/j.memsci.2006.11.019

[13] Taurozzi JS, Arul H, Bosak VZ, Burban AF, Voice TC, Bruening ML, et al. Effect of filler incorporation route on the properties of polysulfone-silver nanocomposite membranes of different porosities. J Memb Sci 2008; 325: 58-68. https://doi.org/10.1016/j.memsci.2008.07.010

[14] Zhu X, Bai R, Wee K-H, Liu C, Tang S-L. Membrane surfaces immobilized with ionic or reduced silver and their anti-biofouling performances. J Memb Sci 2010; 363: 278286.

https://doi.org/10.1016/j.memsci.2010.07.041

[15] Liang S, Xiao K, Mo Y, Huang X. A novel ZnO nanoparticle blended polyvinylidene fluoride membrane for antiirreversible fouling. J Memb Sci 2012; 394-395: 184-192. https://doi.org/10.1016/j.memsci.2011.12.040
Das R, Ali ME, Hamid SBA, Ramakrishna S, Chowdhury ZZ. Carbon nanotube membranes for water purification: $A$ bright future in water desalination. Desalination 2014; 336: 97-109. https://doi.org/10.1016/j.desal.2013.12.026

[17] Ganesh BM, Isloor AM, Ismail AF. Enhanced hydrophilicity and salt rejection study of graphene oxide-polysulfone mixed matrix membrane. DES 2013; 313: 199-207. https://doi.org/10.1016/j.desal.2012.11.037

[18] Monticelli O, Bottino A, Scandale I, Capannelli G, Russo S. Preparation and Properties of Polysulfone - Clay Composite Membranes 2006.

[19] Anadão $P$, Sato LF, Wiebeck H, Valenzuela-Díaz FR. Montmorillonite as a component of polysulfone nanocomposite membranes. Appl Clay Sci 2010; 48: 127132. https://doi.org/10.1016/j.clay.2009.12.011

[20] Hwang H-Y, Kim D-J, Kim H-J, Hong Y-T, Nam S-Y. Effect of nanoclay on properties of porous PVdF membranes. Trans Nonferrous Met Soc China 2011; 21: s141-s147.

[21] Rajabi H, Ghaemi N, Madaeni SS, Daraei P, Khadivi MA Falsafi M. Nanoclay embedded mixed matrix PVDF nanocomposite membrane: Preparation, characterization and biofouling resistance. Appl Surf Sci 2014; 313: 207-214 https://doi.org/10.1016/j.apsusc.2014.05.185

[22] Ghaemi N, Madaeni SS, Alizadeh A, Rajabi H, Daraei P. Preparation, characterization and performance of polyethersulfone/organically modified montmorillonite nanocomposite membranes in removal of pesticides. J Memb Sci 2011; 382: 135-147. https://doi.org/10.1016/j.memsci.2011.08.004

[23] Villaluenga JPG, Khayet M, López-Manchado MA, Valentin JL, Seoane B, Mengual JI. Gas transport properties of polypropylene/clay composite membranes. Eur Polym J 2007; 43: 1132-1143. https://doi.org/10.1016/j.eurpolymj.2007.01.018

[24] Defontaine G, Barichard A, Letaief S, Feng C, Matsuura T, Detellier C. Nanoporous polymer--clay hybrid membranes for gas separation. J Colloid Interface Sci 2010; 343: 622-7. https://doi.org/10.1016/j.jcis.2009.11.048

[25] Leszczyńska A, Njuguna J, Pielichowski K, Banerjee JR. Polymer/montmorillonite nanocomposites with improved thermal properties. Thermochim Acta 2007; 454: 1-22. https://doi.org/10.1016/j.tca.2006.11.003

[26] Ahmad AL, Abdulkarim AA, Ooi BS, Ismail S. Recent development in additives modifications of polyethersulfone membrane for flux enhancement. Chem Eng J 2013; 223 246-267.

https://doi.org/10.1016/j.cej.2013.02.130

[27] Lai CY, Groth A, Gray S, Duke M. Preparation and characterization of poly(vinylidene fluoride)/nanoclay nanocomposite flat sheet membranes for abrasion resistance. Water Res 2014; 57: 56-66.

https://doi.org/10.1016/j.watres.2014.03.005

[28] Anadão $P$, Sato LF, Wiebeck $H$, Valenzuela-Díaz FR. Montmorillonite as a component of polysulfone nanocomposite membranes. Appl Clay Sci 2010; 48: 127132.

https://doi.org/10.1016/j.clay.2009.12.011

[29] Ma Y, Shi F, Wang Z, Wu M, Ma J, Gao C. Preparation and characterization of PSf/clay nanocomposite membranes with PEG 400 as a pore forming additive. Desalination 2012; 286: 131-137. https://doi.org/10.1016/j.desal.2011.10.040

[30] Morihama ACD, Mierzwa JC. Clay nanoparticles effects on performance and morphology of poly(vinylidene fluoride) membranes. Brazilian J Chem Eng 2014; 31: 79-93. https://doi.org/10.1590/S0104-66322014000100009

[31] Mierzwa JC, Arieta V, Verlage M, Carvalho J, Vecitis CD. Effect of clay nanoparticles on the structure and performance 
of polyethersulfone ultrafiltration membranes. Desalination 2013; 314: 147-158.

https://doi.org/10.1016/j.desal.2013.01.011

[32] Mierzwa JC, Vecitis CD, Carvalho J, Arieta V, Verlage M. Anion dopant effects on the structure and performance of polyethersulfone membranes. J Memb Sci 2012; 421-422: 91-102.

https://doi.org/10.1016/j.memsci.2012.06.039

[33] International Standard, Plastics-Film and sheetingMeasurement of water-contact angle of corona-treated films first ed (ISO-15989), 2004; 1-12 2004, (n.d.).

[34] Khulbe KC, Feng C, Matsuura T, Kapantaidakis GC, Wessling $\mathrm{M}$, Koops GH. Characterization of polyethersulfone-polyimide hollow fiber membranes by atomic force microscopy and contact angle goniometery 2003; 226: 63-73.

[35] Yin J, Deng B. Polymer-matrix nanocomposite membranes for water treatment. J Memb Sci 2015; 479: 256-275. https://doi.org/10.1016/j.memsci.2014.11.019

[36] Koh MJ, Hwang HY, Kim DJ, Kim HJ, Hong YT, Nam SY. Preparation and Characterization of Porous PVdF-HFP/clay Nanocomposite Membranes. J Mater Sci Technol 2010; 26: 633-638. https://doi.org/10.1016/S1005-0302(10)60098-9

[37] Smolders CA, Reuvers AJ, Boom RM, Wienk IM. Microstructures in phase-inversion membranes. Part 1. Formation of macrovoids. J Memb Sci 1992; 73: 259-275. https://doi.org/10.1016/0376-7388(92)80134-6
[38] Boom RM, Wienk IM, van den Boomgaard T, Smolders CA. Microstructures in phase inversion membranes. Part 2. The role of a polymeric additive. J Memb Sci 1992; 73: 277-292. https://doi.org/10.1016/0376-7388(92)80135-7

[39] Young T-H, Chen L-W. Pore formation mechanism of membranes from phase inversion process. Desalination 1995; 103: 233-247. https://doi.org/10.1016/0011-9164(95)00076-3

[40] Machado PS, Habert A, Borges C. Membrane formation mechanism based on precipitation kinetics and membrane morphology: flat and hollow fiber polysulfone membranes. $J$ Memb Sci 1999; 155: 171-183. https://doi.org/10.1016/S0376-7388(98)00266-X

[41] Garcia-Ivars J, Alcaina-Miranda M-I, Iborra-Clar M-I, Mendoza-Roca J-A, Pastor-Alcañiz L. Enhancement in hydrophilicity of different polymer phase-inversion ultrafiltration membranes by introducing PEG/Al2O3 nanoparticles. Sep Purif Technol 2014; 128: 45-57. https://doi.org/10.1016/j.seppur.2014.03.012

[42] Barth C, Gonçalves MC, Pires ATN, Roeder J, Wolf BA Asymmetric polysulfone and polyethersulfone membranes: effects of thermodynamic conditions during formation on their performance. J Memb Sci 2000; 169: 287-299. https://doi.org/10.1016/S0376-7388(99)00344-0

[43] Zeng G, He Y, Yu Z, Zhan Y, Ma L, Zhang L. Preparation and characterization of a novel PVDF ultrafiltration membrane by blending with TiO2-HNTs nanocomposites Appl Surf Sci 2016; 371: 624-632.

https://doi.org/10.1016/j.apsusc.2016.02.211 